Anais da 3a Semana de Engenharia Civil da

Universidade Federal do Sul e Sudeste do Pará Jan 2020 - v. 2 - n.1

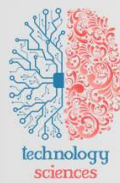

ISSN: 2674-6425

This article is also available online at: www.sapientiae.com.br

\title{
Avaliação das propriedades no estado fresco de argamassas produzidas com resíduos de polipropileno (PP)
}

Devido ao grande volume de resíduos poliméricos, constituiu-se uma ampla problemática na destinação e tratamento adequado dos mesmos. Neste contexto, o objetivo do presente trabalho é analisar a influência da aplicação de resíduos de polipropileno (PP) triturados, provenientes da Cooperativa de Resíduos Sólidos de Tucuruí-PA, nas propriedades da argamassa em seu estado fresco. Para o desenvolvimento da pesquisa, realizou-se a coleta e o beneficiamento do resíduo, os dados obtidos foram analisados através do estudo das propriedades da argamassa em seu estado fresco, determinando sua densidade, consistência e teor de ar incorporado. Com base nos ensaios realizados, observou-se que as misturas apresentaram resultado satisfatório em relação à densidade e teor de ar incorporado para argamassas com PP quando comparadas as argamassas convencionais, entretanto houve perda da consistência. Tendo em vista que a utilização de resíduos poliméricos, embora pouco difundido, percebe-se a importância de estudos com o objetivo de analisar a viabilidade técnica de materiais alternativos enfatizando o conceito de sustentabilidade.

Palavras-chave: Polímero; Polipropileno; Argamassa; Resíduo.

\section{Evaluation of properties in the fresh state of mortar produced with residues of polypropylene (PP)}

\begin{abstract}
Due to the large volume of polymeric residues, a wide problem was found in the proper disposal on its treatment. In this way, the process of reusing the polymer to the applicability, together with the components of the mortar, was studied, in order to determine its properties in the fresh state. Therefore, the objective of the present work is to analyze the influence of the application of crushed polypropylene (PP) residues on the mortar properties in the fresh state, from the Solid Waste Cooperative of Tucuruí. For the development of the research the collection and the processing of the residue were carried out, the obtained data were analyzed through the methodology of the properties in the fresh state, determining its retention of water, consistency and air content incorporated. The results of the samples presented better values in water retention and incorporated air content for PP mortars when compared to conventional mortars, however, there was a loss of consistency. Considering that the use of polymeric residues, although little diffused still produce viable mortars besides proposing the technical feasibility of alternative materials emphasizing the concept of sustainability.
\end{abstract}

Keywords: Polymer; Polypropylene; Mortar; Residue.

Topic: Engenharia de Materiais

Reviewed anonymously in the process of blind peer.
Received: $20 / 11 / 2019$

Approved: 23/12/2019
Adson de Sousa Garcia (D)

Universidade Federal do Pará, Brasil

http://lattes.cnpq.br/2625515093093947

http://orcid.org/0000-0002-8923-3710

adson.ed.garcia@gmail.com

Luís Faruk Entringer de Camargo (iD

Universidade Federal do Pará, Brasil

http://lattes.cnpq.br/0045045351454280

http://orcid.org/0000-0001-9219-3791

farukcaamargo@gmail.com

Bárbara Cristina Soares Silva

Universidade Federal do Pará, Brasil

http://lattes.cnpq.br/8895314168926550

barbarascristina107@gmail.com
Grazielle Tigre de Souza

Universidade Federal do Pará, Brasil

http://lattes.cnpq.br/7162907997815182

grazielle tigre@hotmail.com
Referencing this:

GARCIA, A. S.; CAMARGO, L. F. E.; SILVA, B. C. S.; SOUZA, G. T.. Avaliação das propriedades no estado fresco de argamassas produzidas com resíduos de polipropileno (PP). Technology Science, v.2, n.1, p.66-72, 2020. DOI: http://doi.org/10.6008/CBPC26746425.2020.001.0012 


\section{INTRODUÇÃO}

Os polímeros sempre estiveram presentes no decorrer da história, no entanto, apenas no início do século XX, foram confeccionados os primeiros plásticos sintéticos (PARENTE, 2009). Por caracterização, os polímeros são diferenciados de outros materiais pelo tamanho de suas macromoléculas, estrutura química, e interações intramoleculares e intermoleculares. Estes também podem ser sintéticos, como: poli-isopreno, polipropileno (PP), o poli (tereftalato de etileno) (PET), o polietileno (PE), o poli (cloreto de vinila) (PVC), etc., ou naturais como a seda, a celulose, a fibra do algodão, polissacarídeos, etc. (AKCELRUD, 2007).

Dentre os polímeros existentes, tem-se o polipropileno (PP), que é comumente utilizado na fabricação de para-choques de automóveis, carcaças de eletrodomésticos, recipientes em geral, brinquedos, sacaria, tubo para canetas esferográficas, válvula para aerossóis, materiais hospitalares, indústria automobilística etc. (AKCELRUD, 2007). Devido ao grande volume de resíduos de PP, por seu baixo custo, constituiu-se uma ampla problemática em seu tratamento adequado e destinação. Então, surge a necessidade de estratégias par a reutilização do polímero, evitando impactos ambientais por conta da disposição inadequada de resíduos sólidos (SILVA et al., 2013).

Para o presente estudo, faz-se necessário uma breve definição acerca da argamassa, que consiste em uma mistura homogênea de agregado(s) miúdo(s), aglomerante(s) inorgânico(s) e água, contendo ou não aditivos, com propriedades de aderência e endurecimento, podendo ser dosada em obra ou em instalação própria (argamassa industrializada) (ABNT, 2005). Elas podem ser utilizadas em vários locais com função diferenciada, cada um dos empregos faz jus a uma série de propriedades que corresponde a um tipo de argamassa específico (SANTOS, 2014).

A área de pesquisa com polímeros tem se ampliado e estão sendo realizados vários estudos com a utilização de resíduos dessa natureza em concretos e argamassas, seja como modificadores da pasta de cimento, ou como materiais inertes. Os efeitos no material indicam que a adição de agregado leve de resíduos plásticos na argamassa ou concreto ocasionou principalmente uma redução da trabalhabilidade perda de resistência mecânica e aumento do teor de ar incorporado. Entretanto, ocorreram também a redução do peso específico, do módulo de elasticidade e aumento da ductilidade das amostras com agregado leve de resíduo plástico (MELLO, 2011).

Portanto, a partir da necessidade da reutilização de resíduos poliméricos por conta de fatores ambientais e econômicos, foi realizado o estudo da argamassa em estado fresco contendo PP triturado, proveniente da Cooperativa de Resíduos Sólidos de Tucuruí (PA), para análise das propriedades da argamassa em estado fresco.

\section{MATERIAIS E MÉTODOS}

Para a produção da argamassa foi utilizado o cimento CP II E-32. Como agregado miúdo foi utilizado areia quartzosa com diâmetro máximo de 1,18 mm e resíduo de polipropileno, o qual foi beneficiado de um processo de trituramento fornecido pela Cooperativa de Resíduos Sólidos de Tucuruí. Por fim, a água 
proveniente da Estação de Tratamento de Água da Vila Permanente

Inicialmente foi realizada a determinação da composição granulométrica dos agregados miúdos, seguindo a indicações da NBR 7217 (1987) e sendo representado na Figura 1. Posteriormente, foi realizado o ensaio de massa unitária e especifica, entretanto, para o polímero foi necessário exercer uma adaptação do Frasco Chapman, como pode ser visto na a Figura 2, pois devido à densidade do polipropileno ser menor que a da água, foi necessário utilizar outro meio para que o material decantasse e apresentasse um comportamento mais satisfatório, sendo assim se optou pelo álcool etílico hidratado 70은. INPM. Devido à volatilidade do álcool etílico, considerou-se uma perda substancial (aproximadamente 10\%) em sua massa ao decorrer dos procedimentos do ensaio, através de adaptação de dados (ANDRÉ, 2016).

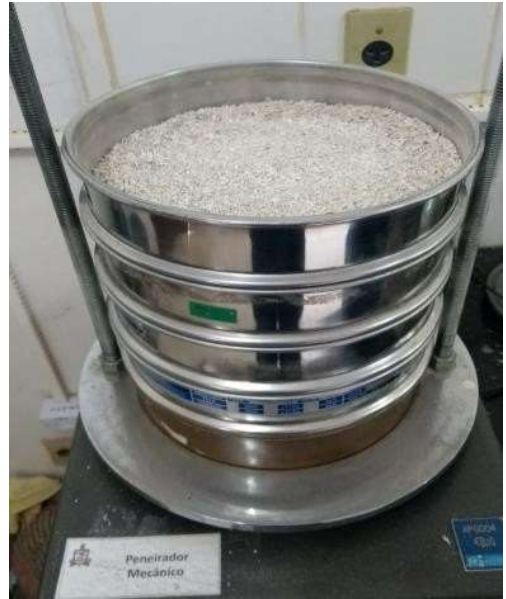

Figura 1: Ensaio de Granulometria do Polipropileno.

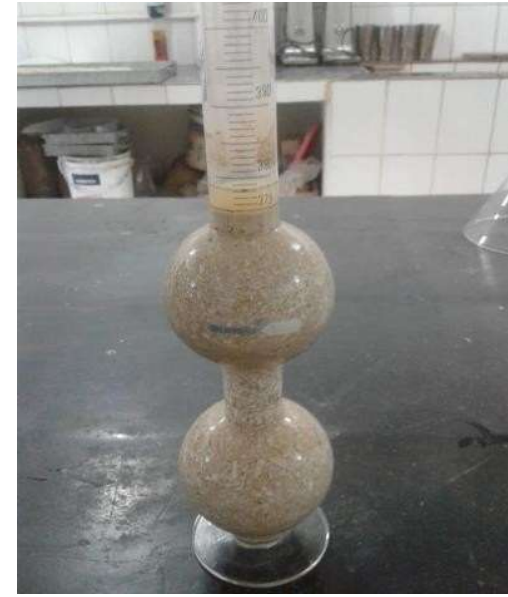

Figura 2: Ensaio de Massa Especifica.

Após a etapa de caracterização dos agregados, estudou-se diversos traços até chegar a um aceitável para o estudo. A relação água/cimento foi definida ajustando a consistência das argamassas para um espalhamento na mesa de consistência (ABNT, 2005). Como pode ser visualizado na Tabela 1, foram feitas substituições na areia por polipropileno nas seguintes proporções em massa: 2,5\%, 5\%, 7,5\% e 10\%.

Tabela 1: Definição dos traços unitários e em massa.

\begin{tabular}{|l|l|l|l|l|l|l|l|l|l|}
\hline Teor de substituição & \multicolumn{2}{l|}{ Cimento } & \multicolumn{2}{l|}{ Agregados miúdos } & & Água \\
\hline & & & Areia & PP & & \\
\hline- & unit. & massa (g) & unit. & massa (g) & unit. & massa (g) & unit. & massa (g) \\
\hline $0 \%$ & 1 & 1000 & 2,5 & 2500 & - & 0 & 0,5 & 500 \\
\hline $2,5 \%$ & 1 & 1000 & 2,4375 & 2437,5 & 0,0625 & 62,5 & 0,5 & 500 \\
\hline $5 \%$ & 1 & 1000 & 2,375 & 2375 & 0,125 & 125 & 0,5 & 500 \\
\hline $7,5 \%$ & 1 & 1000 & 2,3125 & 2312,5 & 0,1875 & 187,5 & 0,5 & 500 \\
\hline $10 \%$ & 1 & 1000 & 2,25 & 2250 & 0,25 & 250 & 0,5 & 500 \\
\hline
\end{tabular}

Seguidamente, iniciou-se os ensaios para a argamassa no estado fresco. Como pode ser visto na Figura 3, verificou-se a trabalhabilidade da argamassa para cada teor de PP através do ensaio da Mesa de Consistência (ABNT, 2016). Em seguida, determinou-se a influência da adição do polímero em relação ao teor de ar incorporado na argamassa, e as demais propriedades no estado fresco 


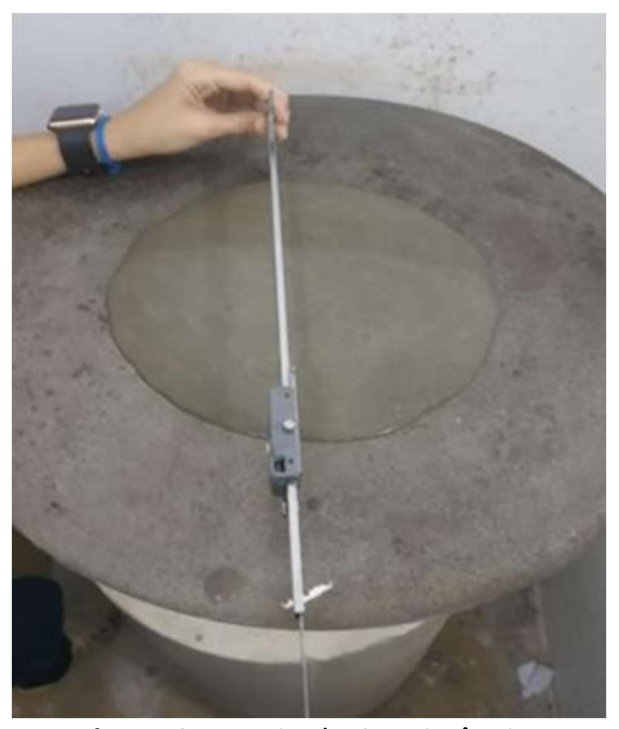

Figura 3: Ensaio de Consistência.

\section{RESULTADOS E DISCUSSÃO}

É possível observar no Gráfico 1 que a granulometria do Polipropileno utilizado apresenta uma curva bem distribuída, o que facilita o preenchimento dos vazios para a confecção da argamassa estudada. A tabela 2 mostra a comparação entre os índices granulométricos e outros parâmetros resultados dos ensaios.

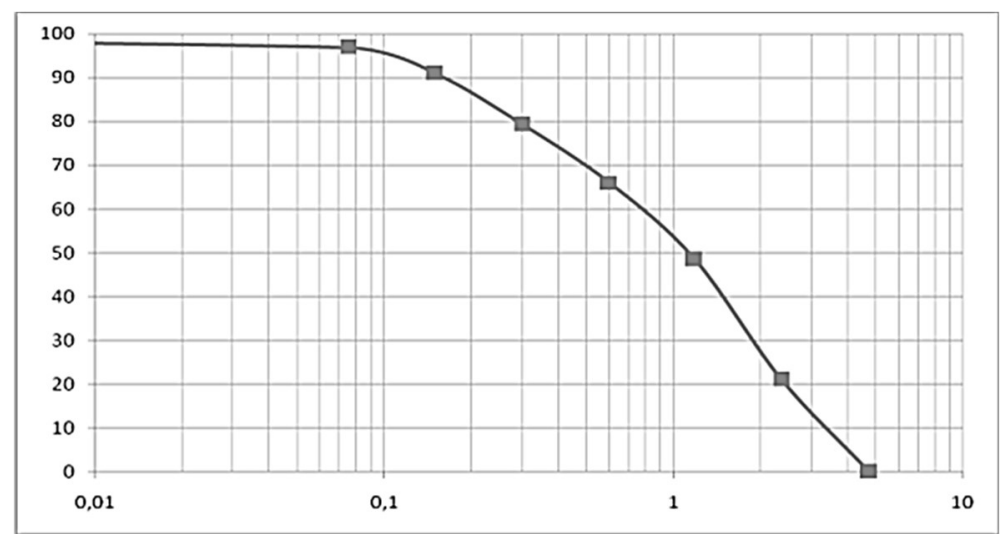

Gráfico 1: Porcentagem retida acumulada do Polipropileno

Tabela 2: Parâmetros físicos dos agregados miúdos.

\begin{tabular}{|l|l|l|l|}
\hline Índices Granulométricos & Métodos & PP & Areia \\
\hline Módulo de Finura & NBR NM 246/2003 & 3,38 & 2,10 \\
\hline Dimensão Máxima $(\mathrm{mm})$ & NBR NM 24/2003 & 4,75 & 1,18 \\
\hline Ensaio & Métodos & PP & Areia \\
\hline Massa unitária $\left(\mathrm{g} / \mathrm{cm}^{3}\right)$ & NBR NM 45/2006 & 0,44 & 1,6 \\
\hline Massa específica $\left(\mathrm{g} / \mathrm{cm}^{3}\right)$ & NBR NM 52/2009 & 0,925 & 2,62 \\
\hline
\end{tabular}

\section{Trabalhabilidade e consistência}

A propriedade de trabalhabilidade, diretamente relacionada à consistência, é a principal característica da argamassa no estado fluido. De acordo com a norma brasileira uma consistência padrão é de $255 \pm 10 \mathrm{~mm}$, variando para cada aplicação. O Gráfico 2 apresenta os resultados dos ensaios realizados do ensaio de consistência feito pela metodologia da NBR 13276 (2016), em que A1, A2 e A3 são as devidas aferições do procedimento. 


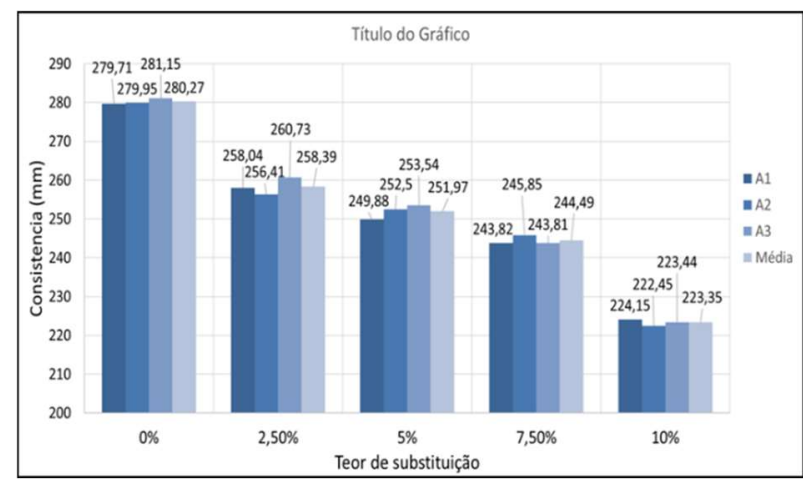

Gráfico 2: Relação Teor de PP substituído/consistência aferida.

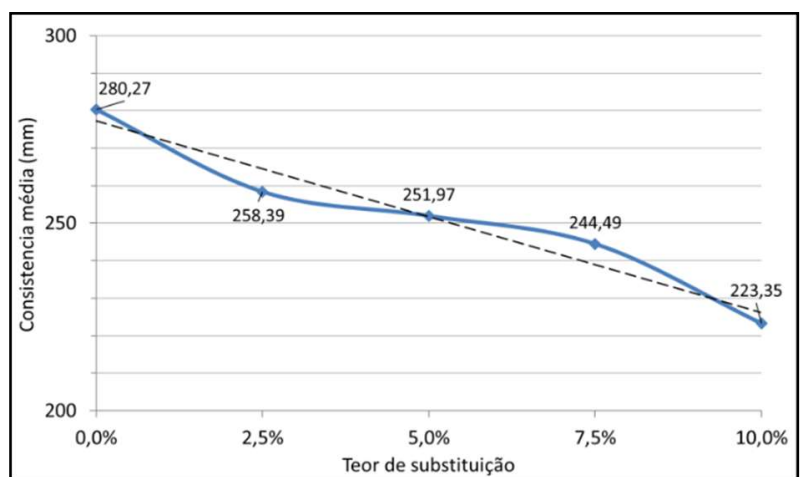

Gráfico 3: Relação Teor de PP substituído/consistência média.

Através de tais dados, é perceptível a influência da substituição da areia por polipropileno (PP) em diversos teores, tendo em vista que o traço de referência obteve uma consistência considerada fluida, com diâmetro maior que $280 \mathrm{~mm}$, e a medida que se substituiu o teor de areia por polipropileno a consistência diminuiu em mesmas proporções, que está mostrado na linha de tendência do Gráfico 3.

Tal tendência determina que quanto maior o teor de PP menor a consistência e vice-versa. Esse fator pode ser atribuído a hidrofobia do polímero que, de acordo com o teor de substituição, diminui a homogeneidade da argamassa, deixando-a com uma textura 'farofada'.

\section{Teor de ar incorporado}

O Gráfico 4, mostra a incorporação de ar em função da substituição da areia convencional pelo polipropileno. É possível notar que essa correlação se apresenta de forma praticamente linear e crescente, o que representa que ao acréscimo de PP, o teor de ar incorporado aumenta proporcionalmente.

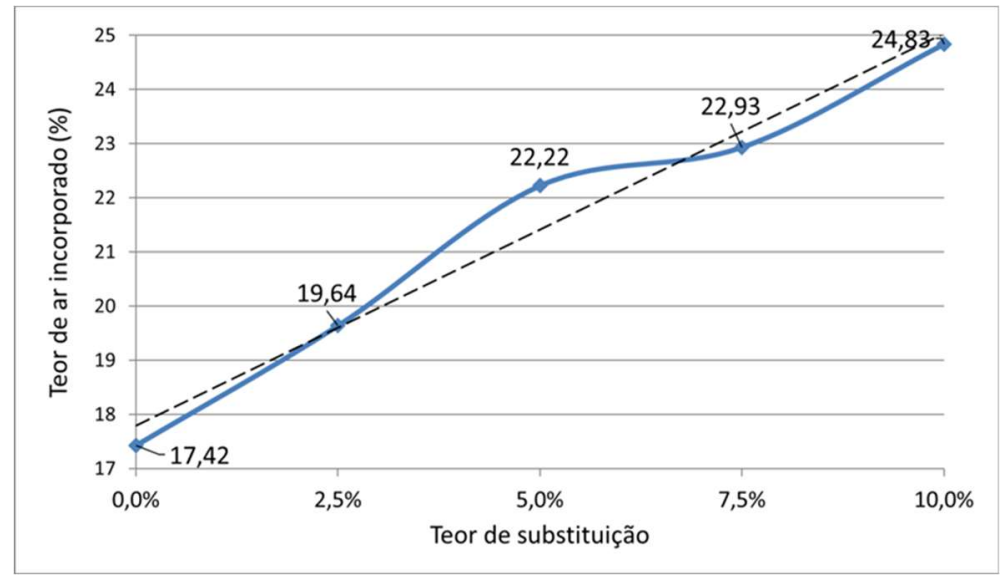

Gráfico 4: Relação Teor de PP substituído/Teor de ar incorporado.

Através de cálculos é possível aferir que essa proporcionalidade apresenta um fator de aproximadamente 0,75 , ou seja, a cada $1 \%$ de polímero incorporado o valor do teor de ar cresce $0,75 \%$. Essa função se deve, provavelmente, à própria porosidade e baixa densidade do PP, o que aumenta o volume e diminui a massa especifica da argamassa. 


\section{Densidade}

O polipropileno por se tratar de um material leve, com massa especifica cerca de $65 \%$ mais baixa que a da areia comum, diminui consideravelmente a densidade da argamassa, quando utilizado como substituição. Isso pode ser observado no Gráfico 5 que mostra um decréscimo na densidade de massa para todas as misturas à medida que é aumentado o teor de PP e, consequentemente, o teor de ar incorporado.

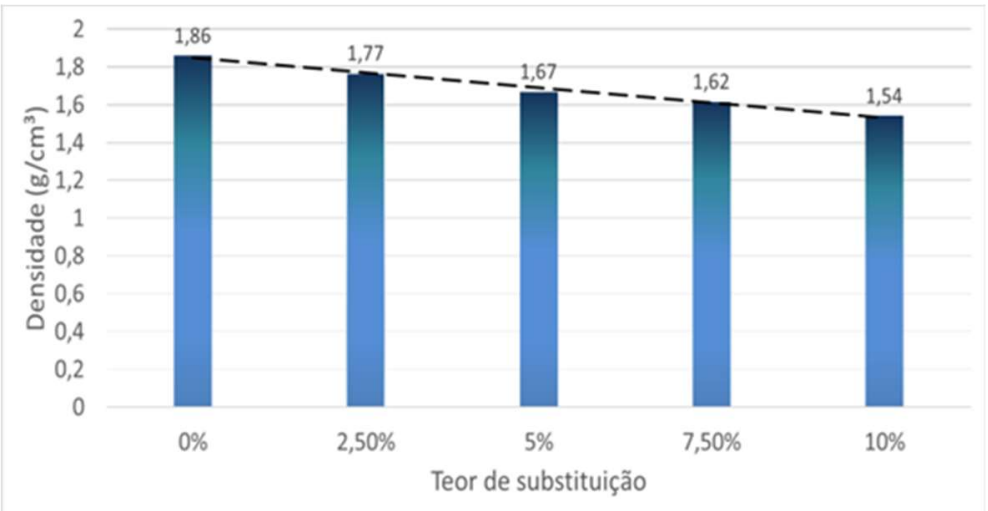

Gráfico 5: Relação Teor de PP substituído/Densidade da argamassa.

\section{CONCLUSÕES}

A partir dos ensaios e análises realizadas, concluiu-se que o material contendo os resíduos avaliados apresentaram grande potencial para confecção de argamassas, como mostra os resultados obtidos. Em relação a trabalhabilidade, foi evidente que quanto maior o teor de PP menor a consistência, o que prejudica diretamente a funcionalidade da argamassa, uma vez que essa é uma propriedade fundamental dela no estado fresco.

Assim como outros resultados obtidos, a incorporação de ar apresentou um comportamento linear e crescente ao introduzir acréscimos de PP, aumentando proporcionalmente. Enquanto a densidade, pode se observar uma diminuição considerável em paralelo com o traço de referência que apresentou o valor de $1,86\left(\mathrm{~g} / \mathrm{cm}^{3}\right)$, ao acrescentar a substituição, obteve-se valores que descressem linearmente de $1,76\left(\mathrm{~g} / \mathrm{cm}^{3}\right)$ até $1,54\left(\mathrm{~g} / \mathrm{cm}^{3}\right)$. Tal fator traz um grande benefício para utilização da argamassa, que é a diminuição do peso próprio, sendo um material mais leve.

Desse modo, a adição de tais resíduos como agregados em argamassas não se restringe apenas à questão ambiental, mas também à possíveis modificações nas propriedades desses compósitos, podendo trazer benefícios nas propriedades materiais do composto. Dessa forma, é imprescindível mais estudos sobre o assunto, nos quais se destacam e se recomendam: Análise utilizando a substituição em parâmetros volumétricos; Ensaios da argamassa com polipropileno no estado endurecido; Analise com outros tipos de resíduos.

\section{REFERÊNCIAS}

AKCELRUD, L.. Fundamentos da ciência dos polímeros. São paulo: Manole Ltda, 2007.

ANDRÉ, T. S.. Taxa de evaporação de combustíveis em função da temperatura: análise termoeconômica aplicada a postos de serviços do RN. Dissertação (Mestrado em Engenharia Mecânica) - Universidade Federal do Rio Grande do Norte, Natal, 2016. 
ABNT. Associação Brasileira de Normas Técnicas. NBR 7217: Agregados - Determinação da composição granulométrica Método de ensaio. Rio de Janeiro: ABNT, 1987.

ABNT. Associação Brasileira de Normas Técnicas. NBR 13276: Agregados - Argamassa para assentamento e revestimento de paredes e tetos - Determinação do índice de consistência. Rio de Janeiro: ABNT, 2016.

ABNT. Associação Brasileira de Normas Técnicas. NBR 13278: Argamassa para assentamento e revestimento de paredes e tetos - Determinação da densidade de massa e do teor de ar incorporado. Rio de Janeiro: ABNT, 2005.

ABNT. Associação Brasileira de Normas Técnicas. NBR 13281: Argamassa para assentamento e revestimento de paredes e tetos - Requisitos. Rio de Janeiro: ABNT, 2005.
MELLO, A. L.. Utilização de resíduos de PEAD como alternativa aos agregados naturais em argamassa.

Dissertação (Mestrado em Engenharia Ambiental Urbana) Universidade Federal da Bahia, Salvador, 2011.

PARENTE, R. A.. Elementos estruturais de plástico reciclado. Tese (Doutorado) - Universidade Federal de São Paulo, São Paulo, 2009.

SANTOS, W. J.. Desenvolvimento de metodologia de dosagem de argamassas de revestimento e assentamento. Tese (Doutorado) - Universidade Federal de Viçosa, Viçosa, 2014.

SILVA, C. O.; SANTOS, G. M.; SILVA, L. N.. A degradação ambiental causada pelo descarte inadequado das embalagens plásticas: estudo de caso. Revista Eletrônica em Gestão, Educação e Tecnologia Ambiental, v.13, n.13, p.2683-2689, 2013.

A CBPC - Companhia Brasileira de Produção Científica (CNPJ: 11.221.422/0001-03) detém os direitos materiais desta publicação. Os direitos referem-se à publicação do trabalho em qualquer parte do mundo, incluindo os direitos às renovações, expansões e disseminações da contribuição, bem como outros direitos subsidiários. Todos os trabalhos publicados eletronicamente poderão posteriormente ser publicados em coletâneas impressas sob coordenação da Sapientiae Publishing, da Companhia Brasileira de Produção Científica e seus parceiros autorizados. Os (as) autores (as) preservam os direitos autorais, mas não têm permissão para a publicação da contribuição em outro meio, impresso ou digital, em português ou em tradução. 